\title{
Synthesis of Heterocyclic Triquinanes via Sequential Radical Cyclizations
}

Gategory

Synthesis of

Heterocycles

Key words

tandem radical cyclization

triquinanes

aza-triquinanes

carbonates

carbamates<smiles>[Y]CC1=CCCC1[X]C([Z])C(C)CCCCOC(=O)OCC</smiles>

$X, Y=O, N T s$

$Z=$ radical precursor

Representative examples:

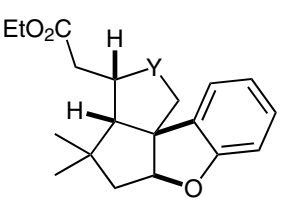

1a $Y=0 ; 61 \%$ yield 1b $\mathrm{Y}=\mathrm{NTs} ; 48 \%$ yield

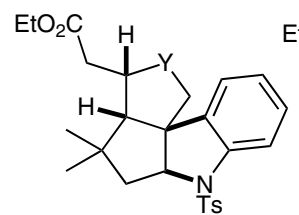

2a $\mathrm{Y}=0$; $67 \%$ yield 2b Y $=$ NTs; $49 \%$ yield

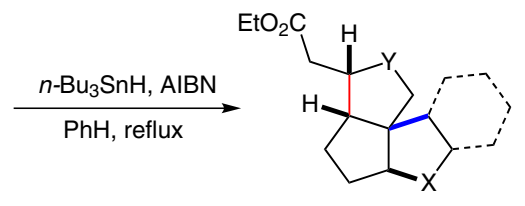

$45-82 \%$ yield $\mathrm{dr} \geq 19: 1$

13 examples

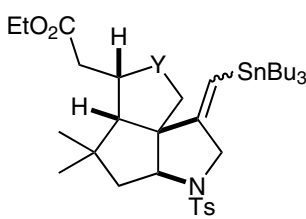

4a $Y=0 ; 81 \%$ yield 4b $Y=$ NTs; $45 \%$ yield

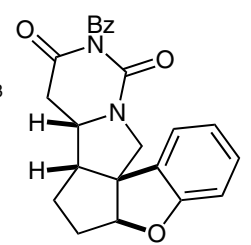

5 55\% yield; $\mathrm{dr} \geq 19: 1$ 3a $X=0 ; 72 \%$ yield

$3 \mathbf{b} X=$ NTs; $70 \%$ yield

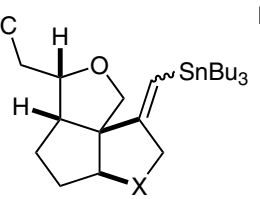

Significance: Tandem radical cyclizations are a powerful synthetic strategy to form polycyclic motifs from acyclic precursors (D. P. Curran Synlett 1991, 63). Numerous synthetic strategies have been applied to the synthesis of all-carbon triquinane frameworks as they are related to various terpene natural product skeletons (G. Mehta, A. Srikrishna Chem. Rev. 1997, 3, 671; V. Singh, B. Thomas Tetrahedron 1998, 54, 3647). Highlighted in this report is the synthesis of angular $\mathrm{O}$ and $N$-triquinanes. The proposed mechanism describes radical initiation using standard conditions from either an aryl iodide or terminal alkyne, followed by successive 5-exo-trig cyclizations. The high level of diastereoselectivity observed in the cyclization is attributed to developing steric interactions observed in the transition state of the second cyclization event. The method affords complex products with a predictable outcome and a high level of stereochemical fidelity in an efficient manner.
Comment: The cyclization precursors are generated using a three-to-four step sequence using standard synthetic transformations in moderate to high yield. The method described is not limited to aryl substitution $(\mathbf{1}, \mathbf{2})$ as exposure of terminal alkyne precursors to the reaction conditions affords vinyl stannane products $(\mathbf{3}, \mathbf{4})$. Proto-destannylation of the aforementioned intermediates using either $\mathrm{SiO}_{2}$ or $\mathrm{TsOH}$ provides the terminal olefin products. The vinyl stannanes are valuable precursors for further functionalization using transition-metal-mediated processes, which was not described. The major drawback to the methodology, due to inherent toxicity issues, is the use of stoichiometric quantities of tin. 